\title{
Demagnetization Analysis of Line-Start Permanent Magnet Synchronous Motors during Its Starting Process
}

\author{
Peijin $\mathrm{Yu}^{1}$, Changqing Zhu ${ }^{1, *}$, Yiming Shen ${ }^{1}$ and Guobin Zhang ${ }^{2}$ \\ ${ }^{1}$ School of Electrical Engineering, Shandong University, China \\ ${ }^{2}$ State Grid Binzhou Branch, China \\ ${ }^{*}$ Corresponding author
}

\begin{abstract}
This paper deals with the analysis for the irreversible demagnetization characteristics of a $\mathrm{NdFeB}$, ' $\mathrm{W}$ type' permanent magnet in the line-start permanent magnet synchronous motors (LSPMSM). By using the finite element method, the influence of different permanent magnets status and the different start voltages on demagnetization were studied during starting process. The largest demagnetization magnetic field was calculated by the minimum value of the projection of flux density in magnetization direction for reference points. Through the comparison of the demagnetization under different conditions, the most serious demagnetization is occurred in low voltage starting process, at the corner points of magnets. It is of great significance to analyze the performance of permanent magnets in actual operation, and it also can be used for the fast design of LSPMSM.
\end{abstract}

Keywords-line-start permanent magnet; starting process; demagnetization; finite method; different start voltages

\section{INTRODUCTION}

Permanent magnet synchronous motors have the advantages of high energy density, high efficiency, and simple structure. With the development of motor technology and the deepening of research on permanent magnetic materials, permanent magnet motors have been widely used in various fields of the national economy. LSPMSM adopts asynchronous self-starting method, with high reliability, small size, and economical operation characteristics. The interaction between the rotating magnetic field of the stator and the squirrel cage rotor generates the asynchronous, so the motor can start by itself. After starting, the rotor runs at the synchronous speed, cage rotor no longer works [1]-[2].

The performance of the permanent magnet motor is largely decided by the performance of the permanent magnet. Demagnetization of the permanent magnet will directly affect the no-load back-EMF and the output torque of the motor. In severe cases, the motor lost excitation ability. The demagnetization is mainly affected by the following factors: temperature, external magnetic field, vibration demagnetization, oxidation, corrosion, and time [3]-[5]. Ref.[3], [6] explain the reasons of the permanent magnet's irreversible demagnetization in derail respectively. The two reasons are the magnetic field of the motor is synthesized by the squirrel cage asynchronous motor effect magnetic field, the variable frequency generator effect magnetic field and the permanent magnet magnetic field and stator current generates a demagnetizing field while squirrel cage bars shield it during start-up. In [7] finite element method was used to simulate the changes of speed and electromagnetic torque in the process of motor starting to verify the correctness of mathematical modeling, however, there are few studies on the variety of permanent magnets in the starting process. Ref.[8] calculated the variety of the average working point of the permanent magnet during the start-up process. The demagnetization point with the highest risk on the permanent magnet could not be involved.

In this paper, finite element method is used to study the demagnetization during starting process under different voltages. Through the analysis of the reference points' radial magnetic density curves over time, the maximum risk demagnetization moment of the permanent magnet in each state is determined, and the permanent magnet magnetic field intensity picture at the corresponding time is plotted, so the demagnetization of each point of the permanent magnet is clearly and intuitively represented. By controlling the voltage at start, the causes of permanent magnet demagnetization was analyzed.

\section{ANALYSIS MODEL}

\section{A. Design Parameters and Model}

This paper takes a 15kW 4-pole LSPMSM [9] as the prototype motor to analyze the demagnetization characteristics under different conditions. Its main parameters are shown in Table I, and the finite element model designed by Ansoft is shown in Figure I. The magnetic structure is 'W-type', yellow and green are represent S-pole and $\mathrm{N}$-pole, respectively.

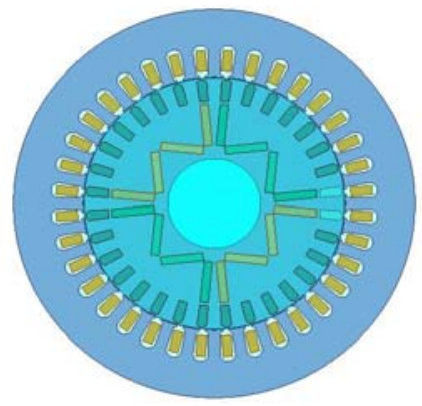

FIGURE I. CROSS-SECTION OF THE PROTOTYPE MOTOR. 
TABLE I. MAIN PARAMETERS OF THE PROTOTYPE MOTOR

\begin{tabular}{|c|c|c|c|}
\hline Parameters & Value & Parameters & Value \\
\hline $\begin{array}{l}\text { Rated line } \\
\text { voltage }\end{array}$ & $380 \mathrm{~V}$ & Rated torque & $95.49 \mathrm{~N} \cdot \mathrm{m}$ \\
\hline $\begin{array}{l}\text { Outer/Inner } \\
\text { diameter of } \\
\text { stator }\end{array}$ & $\begin{array}{c}260 / 170 \\
\mathrm{~mm}\end{array}$ & $\begin{array}{l}\text { Outer/Inner } \\
\text { diameter of } \\
\text { rotor }\end{array}$ & $\begin{array}{c}168.7 / 60 \\
\mathrm{~mm}\end{array}$ \\
\hline Air gap length & $0.65 \mathrm{~mm}$ & $\begin{array}{l}\text { Axial length of } \\
\text { core }\end{array}$ & $190 \mathrm{~mm}$ \\
\hline Core material & DW315-50 & $\begin{array}{c}\text { Number of } \\
\text { stator/rotor slots }\end{array}$ & $36 / 32$ \\
\hline $\begin{array}{c}\text { Permanent } \\
\text { magnet material }\end{array}$ & NTP264H & $\begin{array}{c}\text { Moment of } \\
\text { inertia }\end{array}$ & $\begin{array}{r}0.099 \\
\mathrm{~kg} / \mathrm{m}^{2} \\
\end{array}$ \\
\hline $\begin{array}{l}\text { Coercive force of } \\
\text { permanent } \\
\text { magnet }\end{array}$ & $\begin{array}{l}817.5 \\
\mathrm{kA} / \mathrm{m}\end{array}$ & $\begin{array}{l}\text { Residual flux } \\
\text { density of } \\
\text { permanent } \\
\text { magnet } \\
\end{array}$ & $1.074 \mathrm{~T}$ \\
\hline $\begin{array}{c}\text { Width of } \\
\text { magnets per pole }\end{array}$ & $110 \mathrm{~mm}$ & $\begin{array}{l}\text { Thickness of } \\
\text { magnets }\end{array}$ & $5.3 \mathrm{~mm}$ \\
\hline
\end{tabular}

\section{B. Selection of Reference Points}

Due to the cycle symmetry of the motor, the magnetic flux density changes of the four permanent magnets during the motor starting process have the same tendency. In order to easy to analyze, $\mathrm{N}_{1-4}$ of $\mathrm{N}_{1}$ pole is used as an observation target. The reference points are selected as shown in Figure II. The coordinates of the points in global are $\mathrm{P}_{1}(5.175,52.546)$, P2 $(6.3,38.8)$ and P3 $(9,65.8)$, respectively.

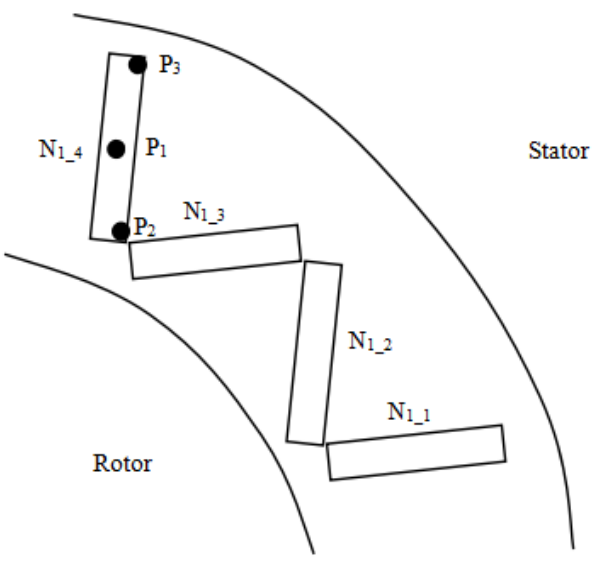

FIGURE II. THE POSITIONS OF REFERENCE POINTS

\section{MAgNetic Field AT No-LOAd RATEd Voltage StarT}

\section{A. The Determination Basis of Demagnetization}

The demagnetization judgment formula can be described as follows.

$$
R=B_{d e m g}-\vec{B} \bullet \frac{\vec{M}}{M}
$$

where $\mathrm{R}$ means the risk of demagnetization, $\mathrm{B}_{\mathrm{demg}}=0$ because there is no knee point in the B-H curve of the permanent magnets at $75^{\circ} \mathrm{C}, \vec{B}$ and $\vec{M}$ are magnetic flux density and magnetization of reference points, respectively.
In (1), When $\mathrm{R}>0$, The motor has demagnetization risk. Because of $B_{\text {demg }}=0$, so we can only consider the radial magnetic density at the reference points. Demagnetization occur when radial magnetic density $<0$, so the judgment of demagnetization simplify.

\section{B. Demagnetization Analysis at the Start of Rated Voltage}

Three-phase voltage source excitation when the rated voltage starts is as in (2).

$$
\left\{\begin{array}{l}
u_{A}=\sqrt{2} \times 220 \sin \left(2 \pi f t+\frac{\pi}{2}\right) \\
u_{B}=\sqrt{2} \times 220 \sin \left(2 \pi f t+\frac{\pi}{2}-\frac{2 \pi}{3}\right) \\
u_{C}=\sqrt{2} \times 220 \sin \left(2 \pi f t+\frac{\pi}{2}+\frac{2 \pi}{3}\right)
\end{array}\right.
$$

When $t=0$, the magnetization direction of the permanent magnet is the same as that of the A-phase winding. Figure III shows the relationship between the speed and time during starting. When the prototype motor starts at rated voltage, the motor speed rises fast and enters synchronization after a brief fluctuation. The start process takes about $285 \mathrm{~ms}$. By observing radial magnetic density curves over time of the three reference points during this process, some rules about the demagnetization of permanent magnets in this motor have been discovered. It can be seen from Figure IV that the risk of demagnetization at the corners of the permanent magnet is greater than the midpoint, and the closer the two permanent magnets are, the greater the risk of demagnetization faces.

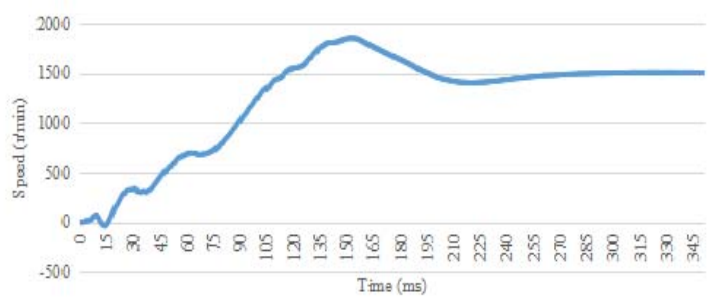

FIGURE III. SPEED CURVE WHEN START AT RATED VOLTAGE

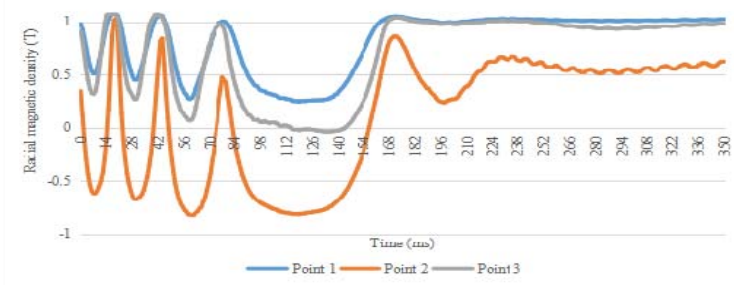

FIGURE IV. RADIAL FLUX DENSITY AT 220V

It can be also seen in Figure IV that the radial flux density variation at different reference points on the one permanent magnet is the same. So we can judge the demagnetization field and its action time in that. For $\mathrm{P}_{2}$, the minimum radial 
magnetic density is $-0.83 T$, at $60 \mathrm{~ms}$, and there is the longest demagnetizing magnetic field during $83 \mathrm{~ms}$ to $163 \mathrm{~ms}$. Figure $\mathrm{V}$ shows the permanent magnet demagnetization at $60 \mathrm{~ms}$. Demagnetization exists in yellow and white areas.

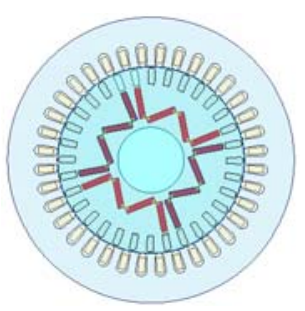

(a) General

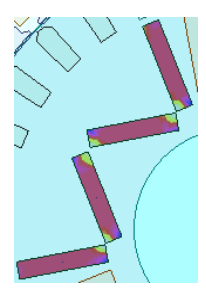

(b) $\mathrm{N} 1$
FIGURE V. PERMANENT MAGNET DEMAGNETIZATION AT 60 MS

\section{Demagnetization Analysis at the Start of DiFFERENT VOLTAGES}

In order to study the effects of different voltages on permanent magnets during no-load start-up, the effective values of the starting voltage are set at $176 \mathrm{~V}, 198 \mathrm{~V}, 220 \mathrm{~V}$, $242 \mathrm{~V}$ and $264 \mathrm{~V}$, respectively. The curves in the figure are denoted as 0-176, 0-198, 0-220, 0-242, and 0-264, respectively. Figure VI shows the speed-time curves and the radial flux density curves at $\mathrm{P}_{2}$ under different start voltage is shown in Figure VII. It can be seen from the figures that with the increase of the starting voltage, the starting process is faster, and the time for the motor to enter the synchronous speed is shortened. The demagnetization field at high voltage start is similar to it at low voltage, and the time for acting on the permanent magnet is short, so the risk of demagnetization is higher for low voltage starting.

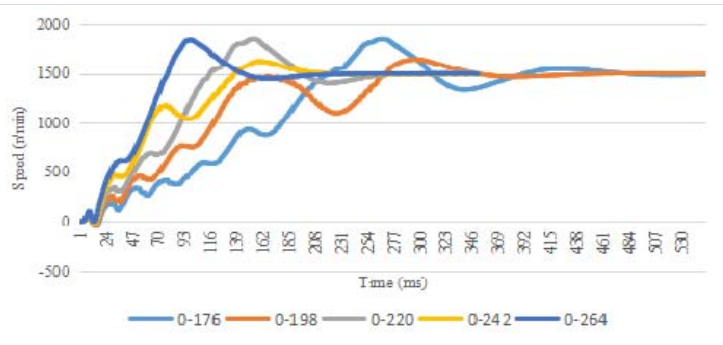

FIGURE VI. SPEED CURVES UNDER DIFFERENT START VOLTAGE

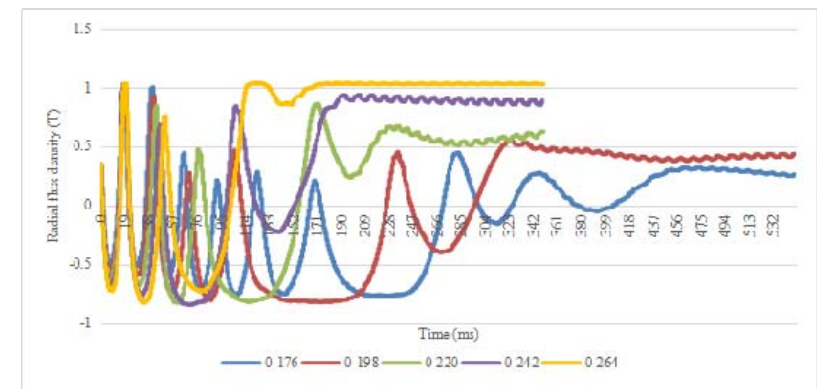

FIGURE VII. RADIAL FLUX DENSITY UNDER DIFFERENT START VOLTAGE

Table II shows some details about the minimum radial flux density and total time of demagnetization during start-up. Based on the Table II, the following conclusions are drawn:
The demagnetization risk of the permanent magnet is larger in lower starting voltage, because the total time of demagnetization at start voltage below the rated one is much longer than it at higher voltage. While the start voltage increase, the biggest risk time occurred earlier, and the values of minimum radial flux density have not change much. This conclusion further proves that the risk of demagnetization of permanent magnets is not only affected by the intensity of the demagnetizing field, but also related to the duration of the action.

TABLE II. RADIAL FLUX DENSITY AT DIFFERENT START VOLTAGE

\begin{tabular}{|c|c|c|c|}
\hline $\begin{array}{c}\text { Start } \\
\text { voltage }\end{array}$ & $\begin{array}{c}\text { Minimum } \\
\text { radial flux } \\
\text { density }\end{array}$ & $\begin{array}{c}\text { Occurred } \\
\text { time }\end{array}$ & $\begin{array}{c}\text { Total time of } \\
\text { demagnetization }\end{array}$ \\
\hline $176 \mathrm{~V}$ & $-0.77 \mathrm{~T}$ & $225 \mathrm{~ms}$ & $278 \mathrm{~ms}$ \\
\hline $198 \mathrm{~V}$ & $-0.82 \mathrm{~T}$ & $172 \mathrm{~ms}$ & $241 \mathrm{~ms}$ \\
\hline $220 \mathrm{~V}$ & $-0.83 \mathrm{~T}$ & $60 \mathrm{~ms}$ & $129 \mathrm{~ms}$ \\
\hline $242 \mathrm{~V}$ & $-0.84 \mathrm{~T}$ & $68 \mathrm{~ms}$ & $110 \mathrm{~ms}$ \\
\hline $264 \mathrm{~V}$ & $-0.83 \mathrm{~T}$ & $33 \mathrm{~ms}$ & $84 \mathrm{~ms}$ \\
\hline
\end{tabular}

\section{CONCLUSION}

In this paper, a model of $15 \mathrm{~kW}$, 4-pole, 'W-type' line-start permanent magnet synchronous motor, which is established using the finite element method, is used to analyze the influence of the different initial conditions on the demagnetization during starting. The main conclusions are as follows.

(1) Permanent magnets are easier to demagnetize at the corners than at the center. In ' $\mathrm{W}$ - type' permanent magnet, the nearer the interval between the two permanent magnets in the same pole, the greater the risk of demagnetization.

(2) Based on the above conclusion, select a permanent magnet corner point as a reference point. By analyzing the radial flux density curves of the corner point of the permanent magnet, it is concluded that the demagnetization risk of the permanent magnet increases with the decrease of the starting voltage at no-load starting under different voltages.

(3) The risk of demagnetization of permanent magnets is not only affected by the intensity of the demagnetizing field, but also related to the duration of the action.

\section{REFERENCES}

[1] Xiuhe Wang, "Permanent magnet motor(2th)” ,China: China Electric Power Press, 2011. (in Chinese)

[2] Xiuhe Wang, Yubo Yang, Changqing Zhu. "Line-start permanent magnet synchronous motors”, China: Chian Machine Press, 2009, pp. $159-161$.

[3] Weifu Lu, "Calculation and analysis of demagnetizing magnetic field in starting process of self-starting permanent magnet synchronous motor", Proceedings of the CSEE, vol. 31, no. 15, pp. 53 - 60, 2011.

[4] Yubo Yang, Xiuhe Wang, Wei Song. "Study on the performance sensitivity to ambient temperature for permanent magnet synchronous motor used in pump jack”, in Proc. ICEMS, Beijing, China, 2003, pp.116 - 119 .

[5] Junqiang Xing, Fengxiang Wang, Tianyu Wang. "Study on antidemagnetization of magnet for high speed permanent magnet machine”, IEEE Transactions on Applied Super conductivity, vol. 20, no. 3, 2010, pp. $856-860$. 
[6] Guodong Fan. "Permanent magnet demagnetization in permanent magnet synchronous motors", M.S. thesis, Dept. Electron. Eng., Shandong University, China, 2010.

[7] Zengcheng Bai, Xueyan Han, Renyuan Tang. "Analysis of asynchronous starting process of permanent magnet synchronous motor", Electric Engineering, vol. 4, 2008, pp.19-22.

[8] Xu Tang,Xiuhe Wang. “Calculation of magnets' average operating point during the starting process of line-start permanent magnet synchronous motor”, in ICEMS, Hangzhou, China, 2014, pp. 2147-2150.

[9] Renyuan Tang. "Modern permanent magnet machines", China: China Machine Press, 2015, pp. 215-233.(in Chinese)

[10] Bo Zhao, Hongliang Zhang. “Ansoft 12 application in engineering electromagnetic fields”, China: China Water Power Press, 2013. 